\title{
Creativity in Prototypes Design and Sustainability - The case of Social Organizations
}

\author{
Clara Silveira ${ }^{*}, 1$ Leonilde Reis², Vitor Santos ${ }^{3}$, Henrique S. Mamede $^{4}$ \\ ${ }^{1}$ School of Technology and Management, Polytechnic Institute of Guarda, Guarda, 6300-559, Portugal \\ ${ }^{2}$ School of Business Administration, Polytechnic Institute of Setúbal, Setúbal, 2914-503, Portugal
}

${ }^{3}$ NOVA Information Management School (NOVA IMS), Lisboa, 1070-312, Portugal

${ }^{4}$ INESC TEC, Universidade Aberta, Lisboa, 1269-001, Portugal

\begin{tabular}{l} 
A R T I C L E I N F O \\
\hline Article history: \\
Received: 07 October, 2020 \\
Accepted: 04 December, 2020 \\
Online: 16 December, 2020 \\
\hline Keywords: \\
Creativity \\
Design \\
Sustainability \\
Social Organization \\
\end{tabular}

A B S T R A C T
The role of creativity techniques in the design of prototypes is of particular interest given
its potential for innovation. At same time, despite the efforts of decades in terms of policies
and programs of action, humanity has not yet come close to global sustainability.
Sustainability design must involve society and creatively employ all available knowledge
sources for creating sustainable software. This paper proposes a prototype design
approach rooted in employing creativity techniques, while being guided by the dimensions
and principles of the Karlskrona Manifesto. This approach is applied to the development
of a multidisciplinary aggregator for the optimization of social services. As a result.
guidelines for the use of creativity in requirements engineering will be presented, as well
as on how to include sustainability issues, namely the Sustainable Development Goals and
the five dimensions of sustainability in the design of prototypes.

\section{Introduction}

This work is an extended version of the paper [1] originally presented in 15 th Iberian Conference on Information Systems and Technologies (CISTI 2020).

The software industry has become extremely competitive. Often, a choice is made between multiple software systems that strive to meet the needs of users in the same application domain. Therefore, in order to be sustainable and grow in the market, a software product needs to differentiate itself from other similar products and captivate users with new and useful features. Given such context, the use of creativity techniques is a determining factor for those who develop software. In Grady Booch's opinion [2], the nature of the systems we build continues to change and as they cross collectively in our lives, we must take into account not only the technical elements of software development, but also human needs. The use of creativity techniques allows requirements engineers to deal with new problems and domains, unique contexts, new applications and a combination of existing methods and techniques [3], [4]. However, research on how the application of creativity occurs has been neglected. Various creativity

${ }^{*}$ Corresponding Author: Clara Silveira, Polytechnic of Guarda, mclara@ipg.pt techniques, such as Brainstorming, scenario generation and simulations, and ad hoc design can be used to support and promote creativity in the requirements engineering process [3].

The Karlskrona Manifesto [5] and other authors [6]-[11] gave visibility and increased awareness of the importance of sustainability in software and Information Systems (IS). Specifically, the Karlskrona Manifesto for Sustainability Design (KMSD) serves as a guide for designing and developing sustainable software systems. Thus, the study of sustainability in the area of software development and IS is of extreme importance in promoting good sustainability practices and the integration of the 17 Sustainable Development Goals (SDGs) defined by the United Nations [12].

This study aims to describe the Creative process and techniques to be used in the design of integrative prototypes for a Social Organization, taking into account sustainability issues and the SDGs.

The paper is organized into five sections. After the introduction, the fundamentals and motivation for using creative techniques in the design of software prototypes are presented, as well as the principles of the Karlskrona Manifesto. Section three 
describes the proposed approach. Next, section four presents a case of applying the approach to a social organisation as well as the proposal for a prototype in relation to the specificity of the problem. Finally, in the last section, the conclusions are presented, as well as the perspectives of future works, showing the spaces still open in the field of work development.

\section{Creativity and Sustainability Design}

\subsection{Creativity in Requirements Engineering}

The field of software engineering, especially requirements engineering, is extremely creative. However, professionals and researchers seem to have different perceptions about creativity, making knowledge transfer difficult [13]. The types of knowledge that we find in the literature that impact creativity from the perspective of software engineers are classified as [14]: previous knowledge, analogies and dynamic knowledge.

Prior knowledge ensures useful information about previous projects for the early stages of ideas generation. This background information provides a starting point or motivation to start with ideas for solving the problem. Analogies help software engineers create a link between two objects in the same or another domain and create new ideas. Dynamic knowledge refers to the knowledge embedded in the tools and available at any time.

We also emphasize that knowledge itself is creative [15] and, therefore, should be encouraged to develop. Results from various experiments show that creativity during the design phase can be improved with the help of analogies [16]. Robert Sternberg [17] defines creativity as the ability to produce work that is simultaneously new (i.e., original and unexpected) and appropriate (i.e., useful and adaptable).

It is also considered that the design of the prototype must contemplate aspects of creativity, including also the concern with the level of comprehensiveness of the information in face of the organizational reality. One concern focuses on the excessive coverage underlying duplication of information [18]. Such a situation can occur when there are duplicates in the individual sources.

In this sense, prototypes must be created to stimulate the creativity of the actors. It may be useful to think about the possible causes of prototype coverage [18], when compared to the target population. Therefore, it is considered essential that a prototype is developed based on research, knowledge, analogies, creative techniques, sustainability factors and, ultimately, validated to answer if it works as specified [19].

Thus, given the specificity of the organization used in this study (of a social nature), it is considered that the purpose of a prototype [19], is to create a semi-realistic representation of something in order to be able to interact and be tested with end users. Its main function is to identify problems and opportunities for improvement long before implementation begins. As it is an agile and efficient method, prototyping will help to define and include more assertiveness in problem solving.

Within the scope of the works related to the thematic area and considering the objective of the paper, practical works developed in organizational context are cited, ([1], [3], [4]).

\subsection{Sustainability Design for Software Development}

The concept of sustainability is often extrapolated to software engineering with the KMSD [5]. The KMSD principles cover several aspects of sustainability, serving as a point of reference and guide during the software design process [20].

The KMSD manifesto appeared at the Third International Workshop on Requirements Engineering for Sustainable Systems (RE4SuSy), held in Karlskrona, Sweden. It is considered a guide to design and develop more sustainable software systems. The KMSD includes nine principles ( [5], [21]):

- P1.Sustainability is systemic: Sustainability is never an isolated feature. Systematic thinking should be the main focus to include interdisciplinarity.

- P2.Sustainability has multiple dimensions: Advocates the inclusion of the five dimensions (Table 1) in our analysis to be able to understand the nature of sustainability in any situation.

- P3.Sustainability transcends multiple disciplines: Sustainability exceeds several disciplines, working on challenges from several perspectives.

- P4.Sustainability is a concern independent of the purpose of the system: Regardless of the system's development context, sustainability must always be included.

- P5.Sustainability applies to both a system and its wider contexts: Concerned with considering at least two spheres in the design of the system: the sustainability of the system itself and how it may affect the sustainability of the context of the entire system.

- P6.System visibility is a necessary precondition and enabler for sustainability design: Concerned with sharing the vision of the system and its context in different perspectives and with the various levels of abstraction, allowing an informed choice. In this principle, it is important to cite the application of the SharedClearVision pattern [22].

- P7.Sustainability requires action on multiple levels: Consists of researching measures for sustainability that are considered the most effective way to intervene in comparison with other alternative actions.

- $\quad$ P8.It is possible to meet the needs of future generations without sacrificing the prosperity of the current generation: Sustainability innovation can play a key role in defining present and future needs. Thus, it is possible to make options that benefit both the present and the future.

- P9.Sustainability requires long-term thinking: Assess, in the long term, the possible impacts, costs and benefits of decisions made.

The manifesto presents general and abstract principles as well as values of sustainability. The KMSD Manifesto also includes the dimensions (five) shown in Table 1.

Table 1: Karlskrona Manifesto - Sustainability Dimensions [5], [21]

\begin{tabular}{|l|l|}
\hline Dimension & Focus \\
\hline Human & $\begin{array}{l}\text { It focuses on the well-being of the } \\
\text { individual. }\end{array}$ \\
\hline Social & $\begin{array}{l}\text { Refers to social issues like groups of people } \\
\text { and organizations in a community. Social }\end{array}$ \\
\hline
\end{tabular}




\begin{tabular}{|l|l|}
\hline & $\begin{array}{l}\text { responsibility, justice, job, and democracy } \\
\text { are essential elements. }\end{array}$ \\
\hline Economic & $\begin{array}{l}\text { Economic sustainability aims at } \\
\text { maintaining capital and added value. }\end{array}$ \\
\hline $\begin{array}{l}\text { Environ- } \\
\text { mental }\end{array}$ & $\begin{array}{l}\text { The main mission of environmental } \\
\text { sustainability is to improve the well-being } \\
\text { of the person, protecting natural resources } \\
\text { and ecosystems. }\end{array}$ \\
\hline Technical & $\begin{array}{l}\text { Concerned with the longevity of } \\
\text { information, systems, their evolution, } \\
\text { maintenance and innovation. }\end{array}$ \\
\hline
\end{tabular}

The KMSD principles and commitments provide an overview of the various dimensions of sustainability and their relationships. In this way, we consider that they show the impact that concerns with sustainability can have in the design of an information system. We added a new vector, combining creativity with the various dimensions of sustainability, allowing to preserve the environment and achieve new technological innovations in social organizations.

\section{Creative Approach in Prototype Design}

In this section, we describe the creative approach used in prototyping within the framework of a more comprehensive methodology for requirements engineering. Among the various creativity techniques that can be used to support and promote creativity in the design of prototypes, the following were selected by the creativity expert [2], namely: Brainstorming, Brutethinking, Reversal and Ideabox. The selection of these techniques took into account the author's accumulated experience in conducting workshops.

Brainstorming is an idea generation technique, which consists of a meeting designed to encourage the full release of mental activity without restrictions. This technique works so well because, among many other reasons, "ideas call ideas". Other people's ideas are sometimes starting points for our best ideas [3].

The Brutethinking technique [3] is characterized by being a simple process, which develops in four stages: choosing a random word; choose things/elements associated with the randomly chosen word; force a link between the word and the problem and between associations and the problem; relate the ideas obtained and analyze them.

The Reversal technique originates from the transformations that generate ideas. In some cases it is better to think first about the negative and then invert the negative, indicate "the worst" and then revert to "the best" [3]. One of the ways is double inversion: initially the reversal identifies the ways to make the situation worse by realizing what can aggravate the problem, instead of improving it. Then, you make an inversion again, identifying the paths that can lead to the improvement of the situation.

IdeaBox is a tool that allows you to combine the parameters (characteristics, factors, variables or aspects) of a challenge (it can be a prototype) into new ideas.

In the creative approach, it is proposed to integrate multiple existing paradigms, in which the creative contribution results from the integration and combination of different approaches that can interrelate, in the search for the integration, in a single proposal, of different forms of thought about a phenomenon [23]. On the other www.astesj.com hand, still in the context of the creative process, it is essential to mention the importance of the characteristics of the creative product, the different views on the models of creative processes, the role of the field of application, the personal characteristics found in highly creative people and, finally, the socioorganizational aspects involved [24].

And we have to note that [23] the multiple views of creativity are complementary and not mutually exclusive. This suggests that future models of creativity can integrate different sources and diverse individual perspectives. The creative approach proposed here is included in a more comprehensive methodology [3] and focuses on the step "Understanding user requirements and sustainability factors", which aims to apply Brainstorming, Brutethinking and reversal creative techniques to: identify the requirements of the user in a process of seeking a creative and sustainable solution; interaction with stakeholders to identify their needs and find out what needs to be built.

In this approach, existing applications and prototyping are used as a source for collecting and validating requirements. Sustainability principles and commitments are incorporated [5]. The preliminary list of requirements is drawn up, as well as the design of exploratory prototypes. In the analysis of prototypes it is proposed to use the Ideabox creativity technique.

\section{Prototype Design in Social Organization}

The Parish Social Center of the Parish of São Sebastião is a Social organization, founded in 1998 that develops strong intervention in the São Domingos Community (SDC). In his daily intervention integrates food distribution programs, monthly food aid (food products given by individuals and companies), distribution of clothing and hygiene products [25].

\subsection{SDC Characterization}

The organization under study, previously presented, has been the subject of work in the thematic area, contributing to the optimization of established practices [7]. In this sense, a brief characterization of the SDC (Figure 1) is presented to frame the problem.

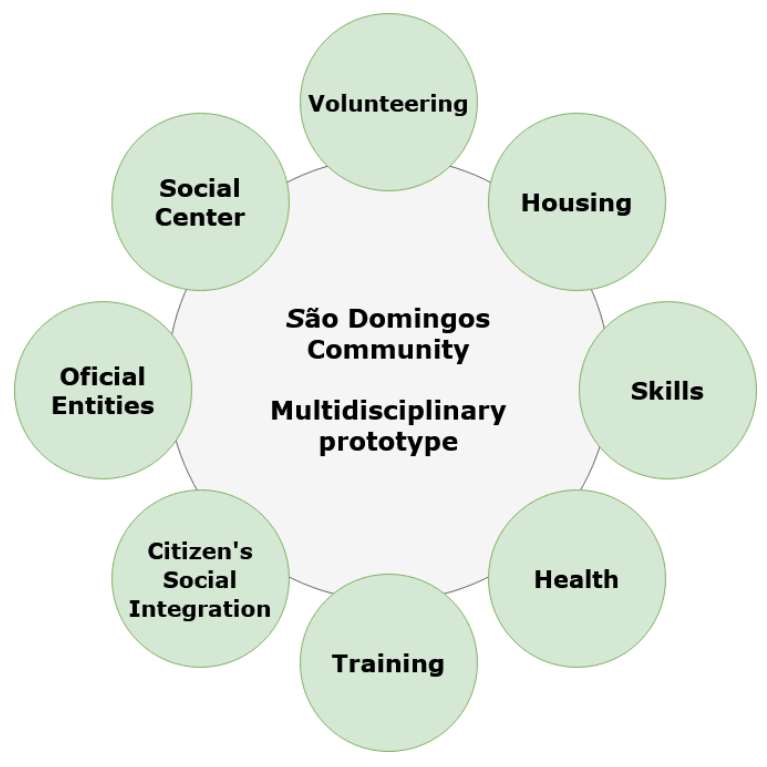

Figure 1: SDC Characterization [7] 
From the meetings between the Project Manager and the SDC Manager and also with the participation of the Software Architect, the organization's current situation was made. The development of the project also had the online collaboration of the Requirements Engineer element.

Figure 1 shows the various aspects that the prototype must include in Housing, Skills, Health, Training, Volunteering for the objective of Social Integration of the Citizen.

In view of the problem under study and the specificity of the social organization under analysis, the team used the Brutethinking technique, in three iterations, to identify the problem, the main objective, the primary causes, the actors of the system and their objectives, the functional and non-functional requirements, creative and non-creative requirements. The Reversal technique was used to prioritize requirements. The team also used the techniques of debate and Brainstorming, in order to evaluate and review artifacts and solutions found. In order to aggregate the information underlying the organization's activity, Figure 1 was conceived in order to highlight the themes involved in a transversal logic of support to the citizen inserted in a community, which, by its nature, has the collaboration of several official entities.

The development of the prototype for SDC was based on a multiple perspectives in order to describe each individual in the various components and taking into account the collaboration of several partners. The valence of volunteering has greater prominence (Figure 2) given the importance of collaboration / interaction of people in the community.

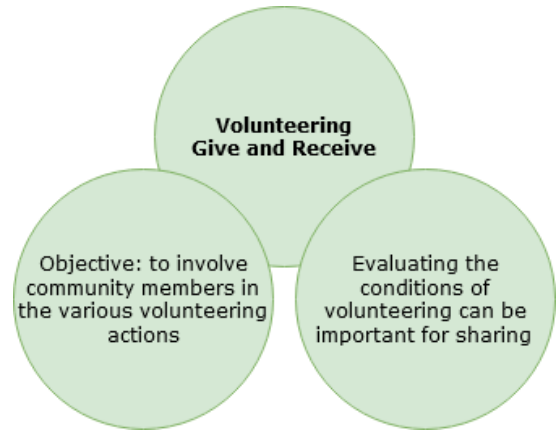

Figure 2: Volunteering characterization

Next, the other objectives and components of Figure 1 are characterized [26]:

- Social Center - support to activities -

- Objective: aggregating skills and knowledge, so that the Social Center can offer high quality and integrated services. The objective is to provide a platform to the various actors, enabling them to access certain SDC data, depending on their access profile;

- Characterization: the platform will allow: managing citizen profile, volunteer members, health professionals; nursing treatments; medication, physical activities; sharing goods and resources; share vehicle and register availability on the platform for volunteering.

\section{- Official Entities - Partnerships}

- Objective: to list the entities with which they will establish partnerships, namely: parish council, health center, Public
Security Police, Foreign Service and Borders. Collaboration with official entities will enable more effective responses to SDC people;

- Characterization: the entity and the manager are identified, the mission, location, preferred contacts, partnership/protocol, association with other stakeholders are described.

- Experience - knowledge kills -

- Objective: an SDC member's life experience (or that of their caregiver), can be valuable information to enhance cooperation with the SDC. Each member's level of literacy is also important so that their skills can be developed, culminating in the sharing of knowledge;

- Characterization: the things a person did throughout their life; the things they like to do and would like to do; the activities they would like to participate in: these can be assessed from one's life experience.

\section{- Resource/car sharing}

- Objective: to allow the sharing/donation of consumer goods or resources (equipment) and car sharing. Reducing carbon emissions and fuel consumption is promoted;

- Characterization: application with resources and goods and availability; places and times to car sharing;

- Health and well-being

- Objective: the aim is to thoroughly characterize the health status of community members, to help with specific and necessary care;

- Characterization: in the various health valences, the importance of aggregating by areas is emphasized: health situation, rehabilitation/physiotherapy, motricity/biomechanics, medical and nursing care, taking medication.

The detailed characterization of the information previously exposed allows to present a multidisciplinary and aggregating vision in order to enhance the provision of services by the Social Center, corresponding to the expectations of its users.

\subsection{Prototypes}

The Social Center, as an entity that aggregates all information and considering the specificity of its mission and its social context, presents needs for collaboration with various entities.

The exploratory prototypes that were presented were conceived using the creative approach, namely the following techniques: Brainstorming, Brutethinking, Reversal and Ideabox. The following principles of the KMSD (described in section 2.2) have also been incorporated: P1; P2; P3; P4; P7 and P9.

Figure 3 shows the exploratory prototype for the main aspects of the Social Center. The prototype multidisciplinary enhances the aggregation of information. The project aims to define an access profile considering data protection concerns within the National Data Protection Commission, an entity that regulates citizens' access to and data protection in Portugal. Figure 3 presents as one of its components Partnerships representing the various entities 
involved in the process, namely the Foreigners and Borders Service in order to support the organization of the process of inhabitants residing in the SDC district. The partners' name is also relevant in this context is social security since there is a regulatory and legal framework in Portugal that enhances the analysis of the economic and professional situation of citizens and families in order to enhance the creation of subsidies, namely the Social Income of Insertion. In this context, the prototype is of particular interest since it aggregates the information in various valences for each citizen and his family.

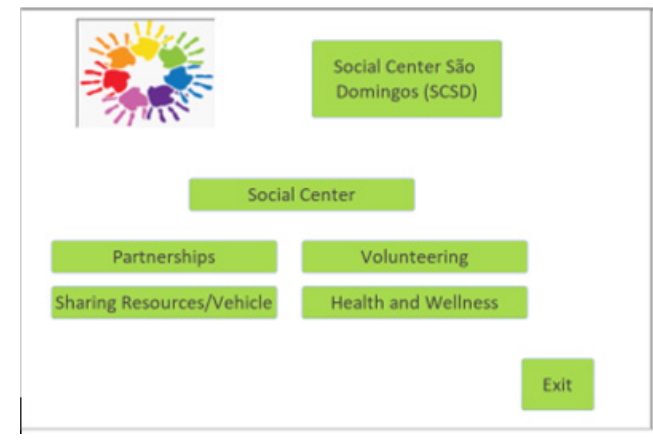

Figure 3: Main menu prototype

The Social Center São Domingos includes a low-level, low-economic community, mainly made up of elderly people with low economic levels, as they are retired people from the manufacturing environment. However, SDC also includes families with adolescents and children with economic needs. Thus, the creation of a prototype of this nature can enhance the centralization of community information in order to allow the delineation of support strategies. Figures 4 present prototypes for Citizen Profile.

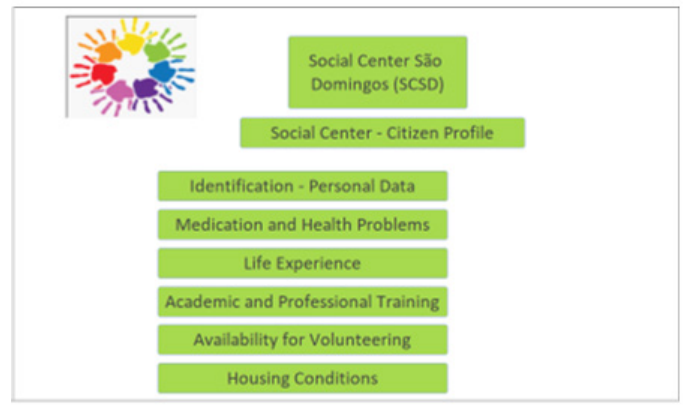

Figure 4: Prototype Citizen Profile

The Citizen Profile characterization aims to collect and keep up to date a set of information referring to each citizen and his family in order to aggregate the various valences. Thus, it is intended a comprehensive characterization with regard to personal data in order to support the various sharing of information in order to create better living conditions. The medication and Health Problems includes the valences of improving the health care of each person, but also knowing the medication necessary to each person in the sense that in case of need the Social Center São Domingos provide its acquisition. Another of the concerns of the Social Center São Domingos is the mobility and conviviality of the elderly in which the Life Experience is an appeal to the sharing of knowledge promoting initiatives that allow to enhance the enormous knowledge of the elderly with other elderly and younger age groups through the organization of workshops and other events. Another aspect of the project focuses on recording in detail the Academic and Professional Training in which the practical experience of each one is emphasized by fostering this sharing through events. This need and also willingness to collaborate and explore the accumulated knowledge has allowed the create of availability for volunteering since it allows the taking of older people from home, enhances collaboration among community members increases the feeling of being useful and actively contributing in their community. Sometimes this collaboration is carried out in exchange for perishable and non-perishable goods increasing also of this were the resources of the family.

The regard to Volunteering - Actions to be promoted - it includes the concerns of involving SDC citizens in concrete voluntary actions. Particularly about the elderly, the objective is to enhance the coexistence and sharing of knowledge. The aspect willingness to receive volunteer support is carried out in actions such as: small reparations in housing, receiving non-perishable goods or other needs that are identified. In view of the sustainability concerns that are intended to be fostered, it is considered that in this context and in view of the specificity of the SDC Sharing - Resources/Vehicles has a view to promoting sustainability by appealing to the implementation of SDGs practices, in particular with regard to the re-use of resources and optimization of car sharing. Regarding Activities - Health and Well-being is intended to promote mobility and active life, as well as to have assertive monitoring particularly with regard to the senior population.

\subsection{Discussion}

The characterization of the SDC is of particular interest in the sense of having the opportunity, within the scope of a partnership, to study a community in order to test the applicability of the creative approach, contributing to the design of the prototype to meet the needs of the organization, although innovative and appropriate.

The prototype underlies the feedback from the team that includes the SDC manager. The creativity techniques Brutethinking, Reversal and Brainstorming were considered adequate for the design. The application of creativity techniques and the incorporation of concerns about sustainability allowed the inclusion of new services: car sharing; resource sharing; take medicine; volunteering; prototype integrating several valences and entities. This corroborates with the authors, in which the involvement and decision of the interested parties in the software project is an integral part of the constructions of software for effective use.

It is considered that the proposed prototype is an aggregator of information based on a multidisciplinary approach allowing the collaboration of several entities taking into account the specificity of intervention of each one so that the Social Center provides a more complete and integrating service.

In terms of sustainability concerns, it is noteworthy, for example, that volunteer actions allow contributing to SDGs as shown in Figure 5. 


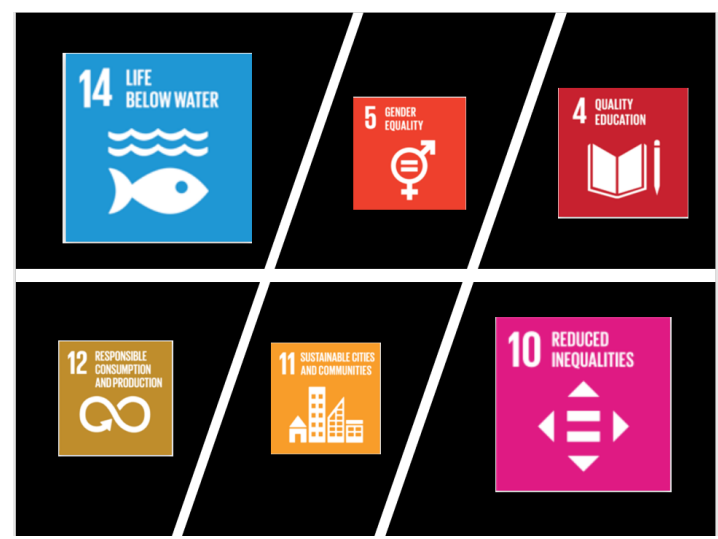

Figure 5: SDGs in the context of volunteering (adapted from [12])

The main contributions to the SDGs are highlighted [12]:

- SDG 4: The prototype under development aims to enhance the participation of young people from the Community of São Domingos to the extent that by getting involved in the various activities they acquire relational and technical skills in the context of their collaboration, even promoting their participation as entrepreneurs;

- SDG 5: The aim of this area is to promote women's empowerment by advocating a set of initiatives. A set of strategies have already been delineated, including short courses on the use of ICT and a financial education course in order to raise women's awareness of the importance of assertive management suggesting in this context the use of ICT to control expenditure;

- SDG 10: The Community of São Domingos has as its strategy inclusive policies given the multicultural provenance of its inhabitants. In this sense, it organizes social events serving the various cultures and religions existing in the neighbourhood.

- SDG 11: The Community collaborate in promoting efforts to protect the world's cultural and natural heritage organizes events;

- SDG 12: Aiming to promote sustainability policies, the Community of São Domingos promotes the distribution of non-perishable goods: clothing, specific health equipment such as wheelchairs and articulated beds and furniture. The Community not only aims to contribute to the well-being of its inhabitants, but also to promote the re-use and recycling of goods;

- SGD 14: Given its geographical location, the Community of São Domingos organizes awareness-raising actions about pollution mainly regarding the Sado River.

It should be noted that the SDGs cannot be analyzed in isolation, since the improvement of one SDGs will have a positive and/or negative impact(s) on another SDGs [27]. Integration adds valuable knowledge that can help society meet the SDGs [28].

\section{Conclusions}

This work presents a proposed approach to the design of prototypes using creativity techniques. It includes a study of a social nature, which contains a set of assumptions that constitute a challenge. Throughout the development of the work, conditions were created for the application and validation of techniques, namely in the field of creativity in IS. In this sense, Brainstorming, Brutethinking, Reversal and Ideabox techniques were applied. Another technique applied in the work was collaboration, where software engineers shared their ideas and thoughts with others. They build on each other's ideas and provide constructive feedback. In this way, it was possible to fill the knowledge gap of each one, creating a group. On the other hand, the principles of the Karslkrona Manifesto have already been applied in several areas [11], [27]-[31].

In this research was possible to apply the theoretical references mentioned to study a real problem, proposing an integrative and multidisciplinary solution in order to enhance the activity of the Social Center in the São Domingos Community in order to provide better services to its community.

As discussed in section 4.3, the results obtained show that creativity techniques can play an important role in transforming of existing Information Systems, bringing innovative and unexpected solutions, which without removing functionality or performance from Information Systems can make them more sustainable.

Therefore, in this context, the understanding that there is an important role to be played by creativity techniques in promoting SDGs and contributing to the development of more sustainable IS is reinforced.

The process was applied in another context [26] and a significant contribution was perceived in the field of sustainability, in the areas: social, individual, economic, environmental and technical [7].

As future work prospects, the case of the chosen Social Organization will be replicated in other communities/institutions in order to contribute to their sustainability. Also, the development of an application to make available to the Social Center is recommended, underlying concerns of a graphic nature, screen design, usability and accessibility. In this sense, solutions are being studied that address the specificities and constraints, particularly financial constraints implicit to social organizations. Thus, the choice of the platform for the development and hosting of information, licenses and maintenance are concerns about the importance of keeping the solution in full operation over time. For the validation of the application we'll use inspection techniques, usability tests and accessibility.

\section{Conflict of Interest}

The authors declare no conflict of interest.

\section{References}

[1] C. Silveira, L. Reis, V. Santos, H. Mamede, "Criatividade no Design de Protótipos - O caso das Organizações Sociais," in CISTI'2020 - 15th Iberian Conference on Information Systems and Technologies, Sevilha, Espanha, 2020, doi:10.23919/CISTI49556.2020.9140870.

[2] G. Booch, "The future of software engineering," in Proc. 37th International Conference on Software Engineering (ICSE 15), 2015.

[3] V. Santos, Criatividade em Sistemas de Informação, Lisboa: FCA, 2018.

[4] V. Santos, L. Amaral, H. Mamede, R. Gonçalves, "Creativity in the Information Systems Planning Process," in Handbook of Research on 
Innovations in Information Retrieval, Analysis, and Management, IGIGlobal, 2015.

[5] C. Becker, R. Chitchyan, L. Duboc, S. Easterbrook, B. Penzenstadler, N. Seyff, C. Venters, "Sustainability Design and Software: The Karlskrona Manifesto," in Proc. 37th International Conference on Software Engineering (ICSE 15), 2015.

[6] Software Sustainability Institute, "Manifesto," 2019. [Online]. Available: www.software.ac.uk/about/manifesto.

[7] L. Reis, C. Silveira, "Sustentabilidade Multidimensional em Sistemas de Informação," in XXX Jornadas Luso-Espanholas de Gestão Científica, Bragança, 2020.

[8] L. Castro, V. Santos, "A perceptional study on the role of development agents and global leaders in leveraging technology for sustainable development," in Multi Conference on Computer Science and Information Systems, 169-176, 2019.

[9] J. Meneses, "A sustentabilidade em 2019," 2019. [Online]. Available: www.bcsdportugal.org/noticias/a-sustentabilidade-em-2019. [Accessed 25 outubro 2019].

[10] S. Hettrick, Research Software Sustainability: Report on a Knowledge Exchange Workshop, The Software Sustainability Institute, 2016.

[11] C. Venters, R. Capilla, S. Betz, B. Penzenstadler, T. Crick, S. Crouch, E. Nakagawa, C. Becker, C. Carrillo, "Software sustainability: Research and practice from a software architecture viewpoint" Journal of Systems and Software, 138, 174-188, 2018. https://doi.org/10.1016/j.jss.2017.12.026

[12] United Nations Development Programme, "Sustainable Development Goals," 2015.2 [Online]. Available: www.undp.org/content/undp/en/home/sustainable-developmentgoals.html. [Accessed 0212 2019].

[13] R. Mohanani, P. Ram, A. Lasisi, P. Ralph, B. Turhan, "Perceptions of Creativity in Software Engineering Research and Practice," in 43rd Euromicro Conference on Software Engineering and Advanced Applications (SEAA), 210-217, Vienna, 2017, doi:10.1109/SEAA.2017.21.

[14] R. Hegde, G. Walia, "How to Enhance the Creativity of Software Developers: A Systematic Literature Review," in International Conference on Software Engineering and Knowledge Engineering, SEKE 2014, 2014.

[15] T. Davenport, L. Prusak, Conhecimento Empresarial, Rio: Campus, 1998.

[16] N. Bonnardel, "Creativity in Design Activities: The Role of Analogies in a Constrained Cognitive Environment," Creativity and Cognition conference, pp. 158-165, 1999.

[17] R. J. Sternberg, Handbook of creativity, Cambridge University Press, 1999.

[18] A. Black, "The IDI prototype spine's creation and coverage," Statistics New Zealand Working Paper No 16-03, 2016.

[19] G. Silvestri, "Prototipação e a criação de produtos que resolvem problemas," 1809 2017. [Online]. Available: https://uxdesign.blog.br/oobjetivo-de-um-protótipo-é-criar-uma-representação-semi-realística-dealgo-que-seja-possível-e0445d85ca93. [Accessed 1802 2020].

[20] B. Penzenstadler, S. Oyedeji, "Experiences from Applying the Karlskrona Manifesto Principles for Sustainability in Software System Design," Proceedings of the 8th International Workshop on Requirements Engineering for Sustainable Systems, 2020.

[21] B. Ovelheiro, C. Silveira, L. Reis, "Sustainability Design Applied to the Digital Signature of Documents," in In Carvalho, L. C., Reis, L., Prata, A., \& Pereira, R. (Ed.), Handbook of Research on Multidisciplinary Approaches to Entrepreneurship, Innovation, and ICTs, IGI Global, 2021, 349-374, doi:10.4018/978-1-7998-4099-2.ch016.

[22] S. Adolph, P. Bramble, Patterns for Effective Use Cases, AddisonWesleyPearson Education, 2003.

[23] R. Stenberg, "The development of creativity as a decision-making process," in Creativity and development V.J.-S. K.., New York, Oxford University Press, 2003, 91-138.

[24] L. Nguyen, G. Shanks, "A framework for understanding creativity in requirements engineering," Information and Software Technology, 51, 655-662, 2009. https://doi.org/10.1016/j.infsof.2008.09.002
[25] CSPSS, "Centro Social Paroquial de São Sebastião," Documento interno, Setúbal, 2019.

[26] C. Silveira, L. Reis, "Sustainability in Information and Communication Technologies," in Handbook of Research on Multidisciplinary Approaches to Entrepreneurship, Innovation, and ICTs, In Carvalho, L. C., Reis, L., Prata, A., \& Pereira, R. (Ed.), IGI Global, 2021, 375-396, doi:10.4018/9781-7998-4099-2.ch017.

[27] L. Reis, C. Silveira, L. Carvalho, C. Mata, R. Madeira, "Design de Protótipo para Pessoa sem-abrigo - Contributos de Sustentabilidade," in IV International Forum on Management, Universidade Aberta. Lisboa, 2020.

[28] P. Shrivastava, M. Smith, K. O'Brien, L. Zsolnai, "Transforming Sustainability Science to Generate Positive Social and Environmental Change Globally," One Earth, 2(4), 329-340, 2020. https://doi.org/10.1016/j.oneear.2020.04.010

[29] S. Oyedeji, A. Seffah, B. Penzenstadler, "A Catalogue Supporting Software Sustainability Design," Sustainability, 10, 2296, 2018 https://doi.org/10.3390/su10072296

[30] B. Penzenstadler, S. Betz, C. Venters, R. Chitchyan, J. Porras, N. Seyff, L. Duboc, C. Becker, "Everything is Interrelated: Teaching Software Engineering for Sustainability," in IEEE/ACM 40th International Conference on Software Engineering: Software Engineering Education and Training, 2018

[31] P. Lago, "Architecture Design Decision Maps for Software Sustainability," in IEEE/ACM 41st International Conference on Software Engineering: Software Engineering in Society, 2019. 